\title{
OPEN Simulation study on radiation exposure of emergency medical responders from radioactively contaminated patients
}

\author{
Takakiyo Tsujiguchi ${ }^{1}$, Yoko Suzuki ${ }^{1}$, Mizuki Sakamoto ${ }^{1}$, Kazuki Narumi ${ }^{1}$, Katsuhiro Ito $^{2}$, \\ Hiroshi Yasuda ${ }^{3}$, Shinji Tokonami ${ }^{4}$ \& Ikuo Kashiwakura ${ }^{1 \bowtie}$
}

Emergency medical responders (EMRs) who treat victims during a radiation emergency are at risk of radiation exposure. In this study, the exposure dose to EMRs treating hypothetically contaminated patients was estimated using a Monte Carlo simulation, and the findings may be useful for educating EMRs and reducing their anxiety. The Monte Carlo simulation estimated radiation doses for adult computational phantoms based on radioactive contamination conditions and radiation dosages from previous studies. At contamination conditions below the typical upper limit of general Geiger-Müller survey meters, the radiation doses to EMRs were estimated to be less than $1 \mu \mathrm{Sv}$ per hour. In cases with greater contamination due to mishandling of an intense radioactive source (hundreds of $\mathrm{GBq}$ ), the radiation doses to EMRs could reach approximately $100 \mathrm{mSv}$ per hour. These results imply that a radiological accident with a highly radioactive source could expose EMR to significant radiation that exceeds their dose limit. Thus, authorities and other parties should ensure that EMRs receive appropriate education and training regarding measures that can be taken to protect themselves from the possibility of excessive radiation exposure. The results of this study may provide EMRs with information to take appropriate protective measures, although it is also important that they not hesitate to perform lifesaving measures because of concerns regarding radiation.

Radiation is widely used in medical and industrial fields. Thus, when nuclear or radiological accidents occur, facility workers and neighboring residents may be exposed to radioactive substances. One example is the Fukushima Daiichi Nuclear Power Plant (FDNPP) accident, which is a well-known nuclear disaster that was assigned the highest rating (level 7) on the International Nuclear and Radiological Event Scale (INES) ${ }^{1-3}$. During the FDNPP accident, $>170,000$ nearby residents were forced to evacuate and emergency medical responders (EMRs) and health physicists were required to perform difficult tasks ${ }^{2}$. In addition to nuclear emergencies, there have been situations that involved contamination and exposure of large numbers of people because of the theft a radiation source, such as the Goiânia accident in Brazil and the Juarez accident in Mexico ${ }^{4,5}$. Improving the medical response to these radiation emergencies requires establishment of international standards for training EMRs and providing them with appropriate radiological protection equipment ${ }^{6,7}$. The exposure doses and patient contamination levels can be estimated using various analyses, which can guide the development of risk prediction models and related risk reduction strategies ${ }^{8,9}$. However, there is little discussion regarding the radiation dose that EMRs may receive from patients while managing a radiation emergency. One example is that contamination inspections are required to comply with the International Atomic Energy Agency (IAEA) technical documents ${ }^{10}$. It is also possible that a highly radioactive source may be powdered and may adhere to patients, as observed during the Goiânia accident. Thus, EMRs are inevitably exposed to radioactive substances from workers and evacuees who are contaminated during a nuclear disaster. In addition, doctors and nurses who provide emergency medicine in this setting have a particularly high risk of radiation exposure.

A recent report described survey responses from EMRs who were dispatched during the FDNPP accident and indicated that they were afraid of being exposed to radiation when they provided emergency care ${ }^{11}$. This anxiety

\footnotetext{
${ }^{1}$ Graduate School of Health Sciences, Hirosaki University, 66-1 Hon-cho, Hirosaki 036-8564, Japan. ${ }^{2}$ Advance Emergency and Critical Care Center, Hirosaki University Hospital, 5 Zaifu-cho, Hirosaki 036-8562, Japan. ${ }^{3}$ Research Institute for Radiation Biology and Medicine, Hiroshima University, 1 Kasumi 2-3, Minami-ku, Hiroshima 734-8553, Japan. ${ }^{4}$ Institute of Radiation Emergency Medicine, Hirosaki University, 66-1 Hon-cho, Hirosaki 036-8564, Japan.『email: ikashi@hirosaki-u.ac.jp
} 


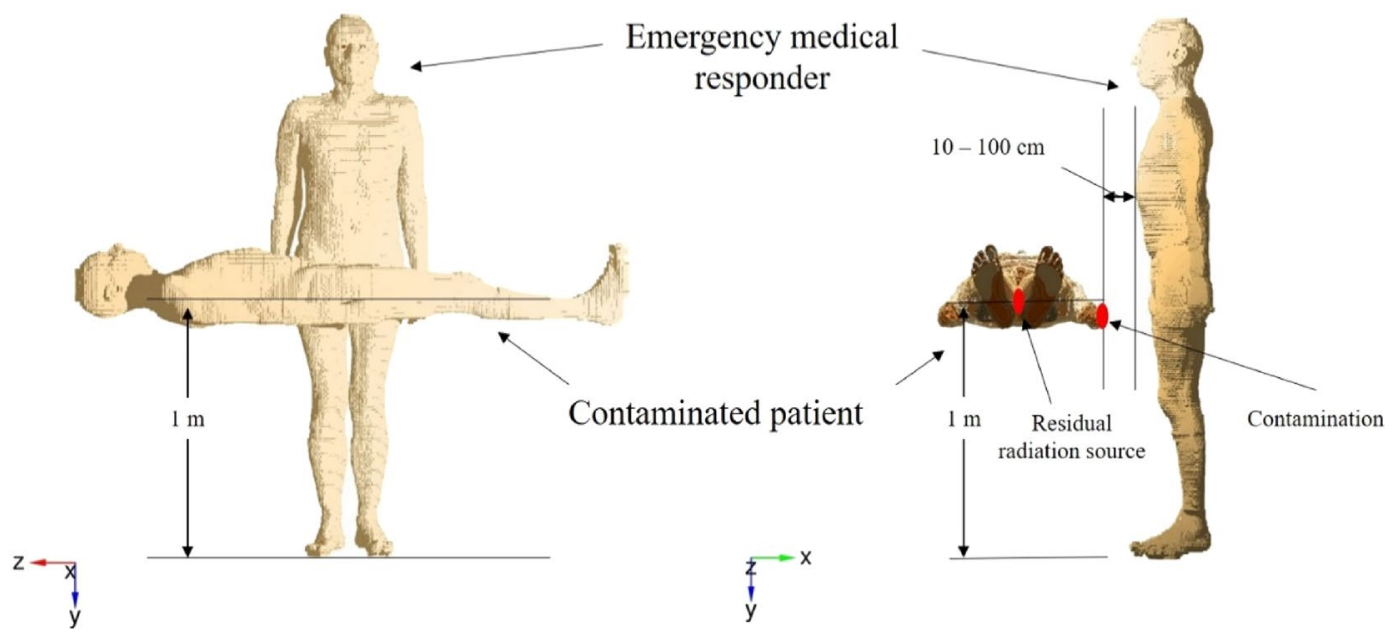

Figure 1. Geometry created using the particle and the heavy ion transport code system. The radionuclides can be set to any location, and the amount of contamination and the distance between the patient and the emergency medical responder can be changed arbitrarily.

during radiation emergencies may impair decision-making, despite the development of emergency response and personnel strategies. Therefore, if a standard exposure dose could be defined for EMRs, specialized education might be implemented to help manage their safety and anxiety, which would allow them to respond calmly and rationally to situations that may involve radiation exposure. This study involved simulation of exposure doses to EMRs who provide emergency care to hypothetical patients who were contaminated by radioactive substances, based on reported information from previous radiation emergencies. The exposure doses to EMRs were estimated using the Particle and the Heavy Ion Transport code System (PHITS) ${ }^{12-14}$, which can calculate photon transport based on various assumptions regarding the radiation emergency and contaminated patient.

\section{Methods}

Monte Carlo code used to simulate the effective dose. A PHITS-based Monte Carlo simulation was performed to estimate the radiation dose that EMRs could receive from contaminated patients ${ }^{12-14}$. The PHITS system can simulate radiation behavior and has been used for various research projects in the fields of medical physics and space engineering ${ }^{15-17}$. A benchmark study regarding photon simulation has been reported for energy ranging from $1 \mathrm{keV}$ to $10 \mathrm{GeV}^{14}$. This PHITS code was used for all physical simulations in the current study.

Creating simulation geometry for the contaminated patient and EMR. An adult computational phantom was created in a virtual space for a hypothetically contaminated patient and an EMR. The adult computational phantom (Reference Computational Phantom-Adult Male) was from ICRP Publication $110^{18}$. Figure 1 shows the actual geometry images created using the PHITS code. Assuming that the contaminated patient was on a stretcher, the trunk center was placed $1 \mathrm{~m}$ above the ground and at a right angle to the EMR. Scenarios were established with adhesion of various radioactive substances to the patient's upper arm or the presence of a radiation source within the patient's abdominal cavity. We calculated the photon scattering from radioactive contamination and the absorbed dose for each of the EMR's organs. Finally, the effective dose was estimated by integrating the absorbed doses for all organs and tissues. The number of simulation trials was set to $10^{7}$ per condition to ensure reliability of the Monte Carlo calculation, and the relative error for each trial was set to $<0.05$ based on a previous report ${ }^{19}$. The simulation assumed that there was no scattering from the floor and walls.

Creating the patient contamination and EMR exposure scenarios. Simulations of emergency medicine and radiation physics require careful consideration of the assumptions. The present study used two general scenarios that were based on previous radiation emergencies: (1) exposure from environmentally released radionuclides and (2) exposure from directly handling a radioactive source. The effective doses to the EMR were calculated for each scenario and the related assumptions are summarized in Table 1.

During nuclear disasters, such as the Chernobyl nuclear power plant (ChNPP) accident and the FDNPP accident, environmentally released radioactive substances (e.g., iodine and cesium) contaminate members of the general population. We defined this situation as Scenario 1 and considered how health physicists might be exposed when they inspected contaminated residents. The assumed contamination level was based on decontamination following Operational Interventional Level 4 (OIL4) from the IAEA technical document ${ }^{10}$. Scenario 1 in Table 1 shows the assumptions regarding contamination concentration and shape.

Scenario 2 involved body surface contamination with radioactive materials that was caused by the theft or mishandling of medical or industrial sources, which occurred during the Goiânia, Juarez, Hanford, and Indiana accidents. Assumptions regarding the amount of contamination in Scenario 2 were based on previously reported 


\begin{tabular}{|c|c|c|c|c|c|}
\hline Scenario & $\begin{array}{l}\text { Situations where responders are } \\
\text { expected to be exposed }\end{array}$ & Radionuclide & $\begin{array}{l}\text { Assumptions regarding } \\
\text { contamination density }\end{array}$ & Shape of contamination & Past cases \\
\hline \multirow{3}{*}{1} & \multirow{3}{*}{$\begin{array}{l}\text { Exposure from environmentally } \\
\text { released radionuclides } \\
\text { - Radionuclides released from } \\
\text { nuclear power plants } \\
\text {-External contamination of evacuees }\end{array}$} & ${ }^{131} \mathrm{I}$ & \multirow{3}{*}{$\begin{array}{l}\text { Assuming } 400 \mathrm{~Bq} / \mathrm{cm}^{2} \text { contamina- } \\
\text { tion on the body surface (approxi- } \\
\text { mately } 100,000 \mathrm{cpm} \text { using a GM } \\
\text { survey meter with a window area } \\
\text { of } 20 \mathrm{~cm}^{2} \text {, which is used to inspect } \\
\text { evacuees for contamination) }\end{array}$} & \multirow{3}{*}{$\begin{array}{l}\text { A circular contamination area with } \\
\text { a radius of } 5 \mathrm{~cm} \text { on the back of the } \\
\text { hand }\end{array}$} & \multirow{3}{*}{$\begin{array}{l}\text { Chernobyl nuclear power plant } \\
\text { accident (USSR, 1986) } \\
\text { Fukushima Daiichi nuclear power } \\
\text { plant accident (Japan, 2011) }\end{array}$} \\
\hline & & ${ }^{134} \mathrm{Cs}$ & & & \\
\hline & & ${ }^{137} \mathrm{Cs}$ & & & \\
\hline \multirow{4}{*}{2} & \multirow{4}{*}{$\begin{array}{l}\text { Exposure from directly handling a } \\
\text { radioactive source } \\
\text {-Illegal handling of a source without } \\
\text { proper protection } \\
\text { •Misuse of a source in industry/ } \\
\text { medicine }\end{array}$} & ${ }^{60} \mathrm{Co}$ & \multirow{2}{*}{$\begin{array}{l}\text { Assuming a } 10-\mathrm{GBq} \text { source on the } \\
\text { body surface }\end{array}$} & \multirow{2}{*}{$\begin{array}{l}\text { Point-source-like contamination on } \\
\text { the back of the hand with a radius } \\
\text { of } 1.25 \mathrm{~cm}\end{array}$} & Goiânia accident (Brazil, 1987) \\
\hline & & ${ }^{137} \mathrm{Cs}$ & & & Juarez accident (Mexico, 1983) \\
\hline & & ${ }^{241} \mathrm{Am}$ & $\begin{array}{l}\text { Assuming a 185-GBq contamina- } \\
\text { tion }\end{array}$ & $\begin{array}{l}\text { A circular contamination area with } \\
\text { a radius of } 5 \mathrm{~cm} \text { on the back of the } \\
\text { hand }\end{array}$ & Hanford accident (USA, 1976) \\
\hline & & ${ }^{192} \mathrm{Ir}$ & $\begin{array}{l}\text { Assuming a 137-GBq source in } \\
\text { the body }\end{array}$ & $\begin{array}{l}\text { Assuming that a } \varphi 1 \mathrm{~mm} \times 5 \mathrm{~mm} \\
\text { radiation source remains in the } \\
\text { abdomen }\end{array}$ & Indiana accident (USA, 1992) \\
\hline
\end{tabular}

Table 1. Assumptions regarding radionucleotides that are attached to a contaminated patient in this study.

information ${ }^{20,21}$ and the radioactivity of radiation sources from common medical or industrial applications. This scenario is not a faithful reproduction of cases from previous radiological accidents, and detailed information regarding the size and area of contamination is shown in Table 1.

Verification of simulation accuracy. Sato et al. ${ }^{13}$ have reported verified benchmarks for radiation and energy that can be used for PHITS-based simulations. Given the importance of confirming deviation from the actual measurement during a physical simulation study, our research group prepared phantoms and other conditions in the reproducible range in an attempt to verify accuracy. We placed a human phantom (PBU-60; Kyoto Giken Kogyo Co., Japan) on a stretcher and attached a sealed ${ }^{60} \mathrm{Co}$ radiation source $(57,200 \mathrm{~Bq}$ at the measurement date) to the phantom's upper arm. The absorbed dose in the air was then measured using a 3-in $\times 3$-in $\mathrm{NaI}(\mathrm{Tl})$ scintillation spectrometer (EMF-211; EMF Japan Co., Japan) at points equidistant from the contamination site, with measurements performed at $10-\mathrm{cm}$ intervals $(10-100 \mathrm{~cm})$ from the contaminated area. The absorbed dose in the air was measured three times over 5-min periods. Similarly, at a distance of $10 \mathrm{~cm}$ from the contaminated site, the spectrometer was installed to perform five readings at $40 \mathrm{~cm}, 70 \mathrm{~cm}, 100 \mathrm{~cm}, 130 \mathrm{~cm}$, and $160 \mathrm{~cm}$ from the floor. The same geometry and cobalt radiation source were also used for the PHITS-based simulations. Accuracy was verified by comparing the measured values to those from the simulation model.

Results

Verifying the accuracy of the simulation model. The measurement and simulation results are shown in Fig. 2. Comparisons of the measured and simulated spectrometer values $(10-\mathrm{cm}$ intervals, $10-100 \mathrm{~cm}$ from the contaminated site) revealed a relative error rate of $<14 \%$ at all points (Fig. 2A). Similarly, the relative error rate of the simulated value was $<14 \%$ when compared to the spectrometer results at various height and a distance of $10 \mathrm{~cm}$ from the contaminated site (Fig. 2B). At each point, the simulated values of the absorbed dose in the air did not underestimate the measured values. Thus, based on acceptable accuracy findings, the simulations were performed to collect the following results.

Estimated exposure dose to EMRs treating contaminated patients. Figures 3 and 4 show the simulation results. In situations where the patient's contamination was below the upper limit of a general Geiger-Müller survey meter, the maximum external exposure dose to the EMR was approximately 33 nSv per hour at a distance of $10 \mathrm{~cm}$ from the contamination (Fig. 3). In situations where the patient might have been contaminated with a powder from a radiation source, the maximum external exposure dose to the EMR was likely less than $16 \mathrm{mSv}$ per hour (Fig. 4A). In situations involving a patient contaminated by high-capacity radiation sources, such as therapeutic radiation sources, the maximum external exposure dose to the EMR was approximately $48 \mathrm{mSv}$ per hour (Fig. 4B). Assuming contamination with ${ }^{241} \mathrm{Am}$ based on the Hanford accident (several hundred $\mathrm{GBq}$ ), the maximum external exposure dose to the EMR was approximately $12 \mathrm{mSv}$ per hour (Fig. 4C).

Estimated times to reach various dose limits. Based on our simulation results, Table 2 summarizes the estimated times to reach various dose limits during planned or emergency exposures that are presented in ICRP Publication 10322. Fig. 5 shows the exposure dose of an EMR at a distance of $10 \mathrm{~cm}$ from the contaminated site when treating a patient in Scenario 2 (theft or mishandling of a medical or industrial radiation source). The IAEA recommends that the average planned occupational exposure dose limit over 5 years should be $\leq 20 \mathrm{mSv}$ per year, and that it should not exceed $50 \mathrm{mSv}$ in any year. Under emergency exposure situations, reference exposure dose limits of $100 \mathrm{mSv}, 500 \mathrm{mSv}$, and $1000 \mathrm{mSv}$ were selected. Based on the simulation results from the two scenarios (Table 1), the expected times to reach exposure dose limits of $1 \mathrm{mSv}, 20 \mathrm{mSv}, 50 \mathrm{mSv}$, or $100 \mathrm{mSv}$ were calculated when treating the patient at a distance of $10 \mathrm{~cm}$ from the contaminated site.

We found that, when the patient's contamination exceeded OIL4, which is expected during a nuclear disaster, the expected time for the EMR to reach an exposure dose of $1 \mathrm{mSv}$ was $>1000 \mathrm{~h}$. However, when the patient was contaminated in Scenario 2 (theft or mishandling of a radiation source), the expected time for the EMR to 

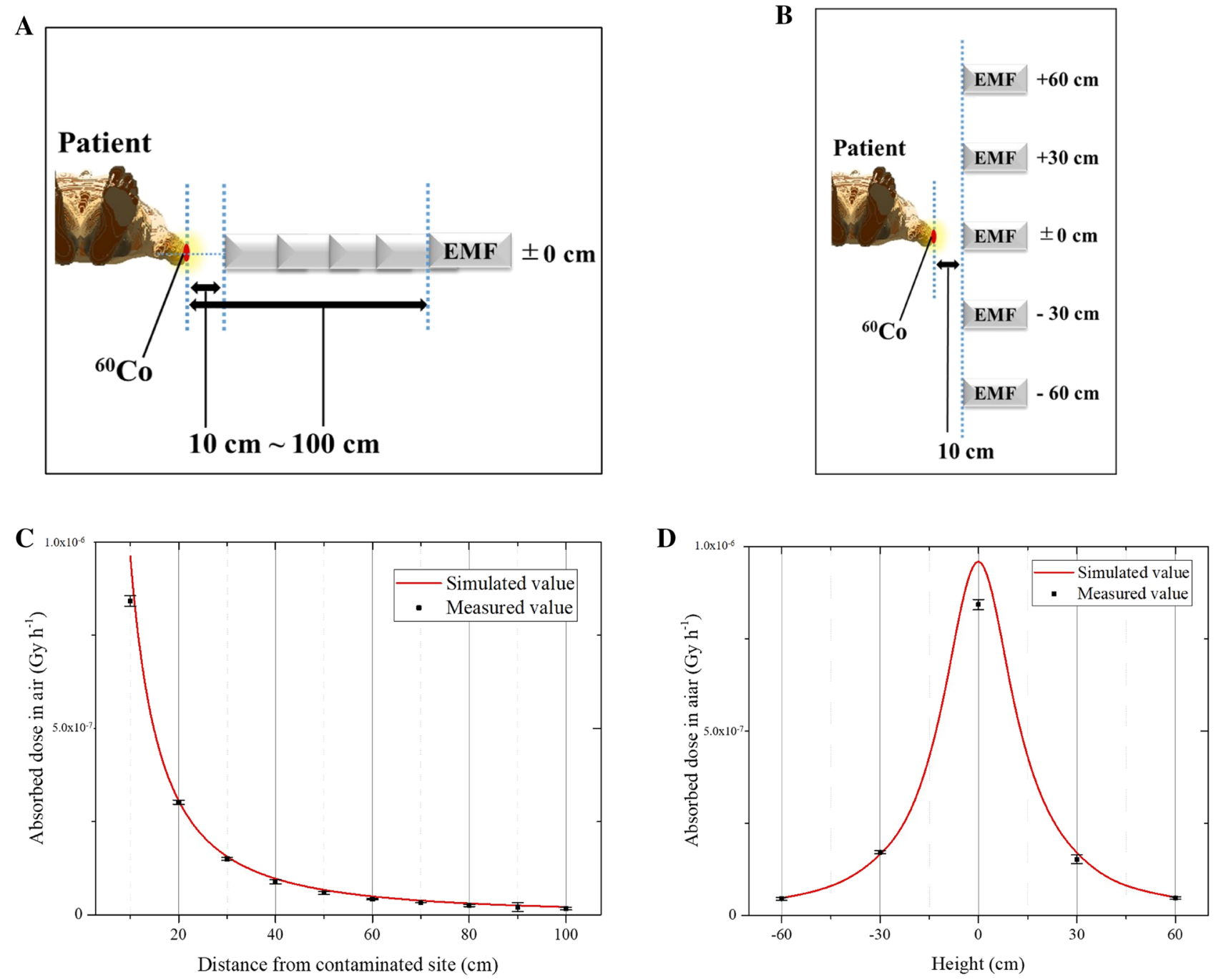

Figure 2. Verifying the accuracy of the simulation model. (A) The outline when the spectrometer was set at 10 - $\mathrm{cm}$ intervals $(10-100 \mathrm{~cm})$ from the contaminated site. (B) The outline when the height of the spectrometer was changed to a distance of $10 \mathrm{~cm}$ from the contaminated site. (C) Comparing the measured and simulated values when the spectrometer was set at $10-\mathrm{cm}$ intervals $(10-100 \mathrm{~cm})$ from the contaminated site and (D) when the height of the spectrometer was changed to a distance of $10 \mathrm{~cm}$ from the contaminated site.

reach an exposure dose of $1 \mathrm{mSv}$ ranged from a few minutes to tens of minutes. In a scenario involving ${ }^{192} \mathrm{Ir}$, an ERM who treated a contaminated patient at a distance of $10 \mathrm{~cm}$ for approximately $2 \mathrm{~h}$ would reach an exposure dose of approximately $100 \mathrm{mSv}$.

\section{Discussion}

Based on the "as low as reasonably achievable" (ALARA) principle, the exposure dose to the public and professionals should be reduced as much as possible under the specific circumstances ${ }^{22-24}$. The ALARA principle is also applicable during radiation emergencies, although its applicability is complicated by the priority of saving the patient's life in these emergencies, and it is important to develop appropriate treatment strategies that incorporate exposure dose evaluations ${ }^{25,26}$. Therefore, although it is not difficult to strictly implement the ALARA principle, this must also factor in the high value of the human life that is at stake in emergency situations. For example, doctors, nurses, and health physicists can conceivably be called upon to treat contaminated victims and evacuees in an emergency situation, which makes it difficult to ensure sufficient distance and time limitations in situations with unknown contamination. Wearing protective clothing can make it difficult to read a personal dosimeter, and even if the dosimeter has an alarm function, the alarm merely indicates that the set dose has 


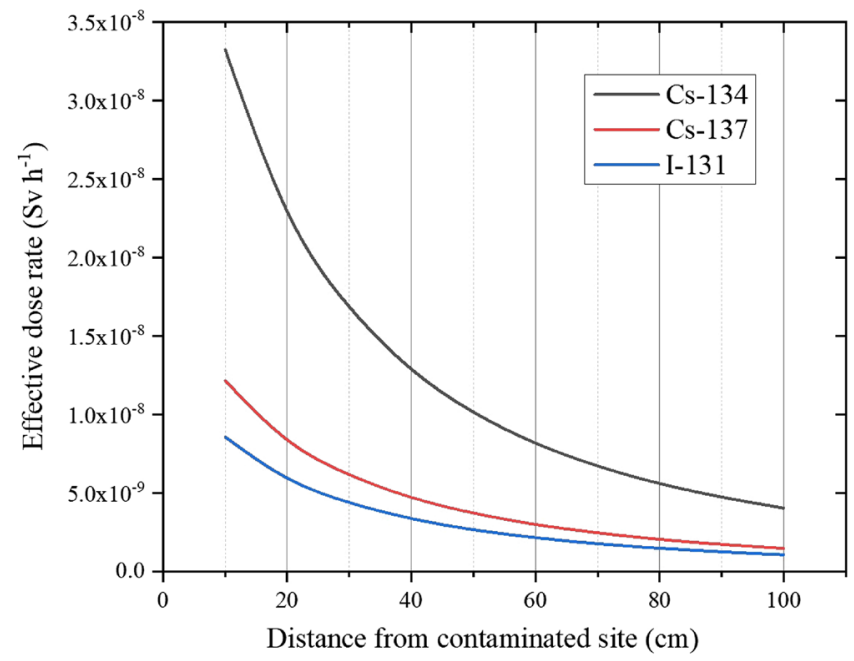

Figure 3. Exposure doses of an emergency medical responder who cares for a patient who was contaminated with radionuclides that are expected to be released during a nuclear disaster. Each of the three sources is on the surface of the body and has an intensity of $400 \mathrm{~Bq} \mathrm{~cm}^{-2}$. Table 1 shows the detailed assumptions for this Scenario (Scenario 1).

been reached. Therefore, simply wearing a personal dosimeter does not predict dose exposure during a radiation emergency, and additional strategies and planning are needed to guide appropriate measures. For example, our findings might be useful for developing guidelines regarding appropriate personnel replacements and limits to activities at the disaster location ${ }^{8}$.

The results of this simulation study were obtained using the PHITS code and established benchmark values. Relative to actual measured values, the simulation values were comparable and did not underestimate the actual values, with a sufficiently reliable relative error rate $(<14 \%)$ (Fig. 2). Based on the simulation results, an EMR who treats a patient with contamination exceeding OIL4 would not realistically exceed the occupational exposure limit, regardless of the time spent treating the patient (Fig. 3, Table 2). However, in cases involving theft or mishandling of radiation sources for medical and industrial applications, the EMR might receive exposure doses of 1-100 mSv (Fig. 4, Table 2). The exposure dose of an EMR who provides radiation emergency medicine is the exposure dose when the contaminated area of the victim is not decontaminated at all. It is necessary to keep in mind that the exposure dose of both the patient and EMR can be reduced by performing appropriate decontamination after the patient's lifesaving measures are taken. Accidents in which a high-radioactivity source is attached to a patient are rare. It is unlikely that exposure to EMR by radioactive substances attached to the patient will cause a deterministic effect. Still, it is important to control the exposure dose for radiological protection.

Several studies have identified anxiety regarding radiation among medical professionals and the importance of education regarding radiological protection. For example, Sato et al. conducted a questionnaire survey of nurses working at core hospitals in Fukushima Prefecture after the FDNPP accident and reported that many nurses were considering retirement or migration because of anxiety regarding radiation and related health effects ${ }^{27}$. Akashi et al. have also recommended promptly providing radiological protection information to Disaster Medical Assistance Teams ${ }^{28}$. Therefore, it is important to provide radiological protection and education to EMRs who respond to radiation emergencies. The 2020 IAEA guidelines also highlight the importance of obtaining assistance from medical physicists with experience in radiation emergencies ${ }^{29}$. Thus, improving the knowledge, anxiety, and capabilities of EMRs is critically important to their radiological protection.

The results shown in Figs. 4 and 5 may be useful reference data for estimating EMRs' exposure doses based on different scenarios involving medical and industrial radiation sources. Although these events are rare, they are not impossible, as observed during the Goiânia accident (in Brazil) and the Indiana accident (in the US). There have also only been two level 7 accidents based on the INES scale, which were the ChNPP accident and the FDNPP accident. Nevertheless, over a 30 -year period, there has been $>600$ radiological accidents with $>2,000$ incidents that involved exposed/contaminated victims ${ }^{30}$. The possibility of other incidents, such as nuclear terrorism, also further highlights the importance of providing appropriate radiological protection for EMRs.

Although radiological accidents or nuclear disasters are rare, they have enormous effects on medical professionals and the general population. Therefore, radiological protection strategies and education forEMRs and related institutions should be considered before these events occur. We believe that the findings of this study will be useful for guiding the development of these radiological protection strategies and related education. 

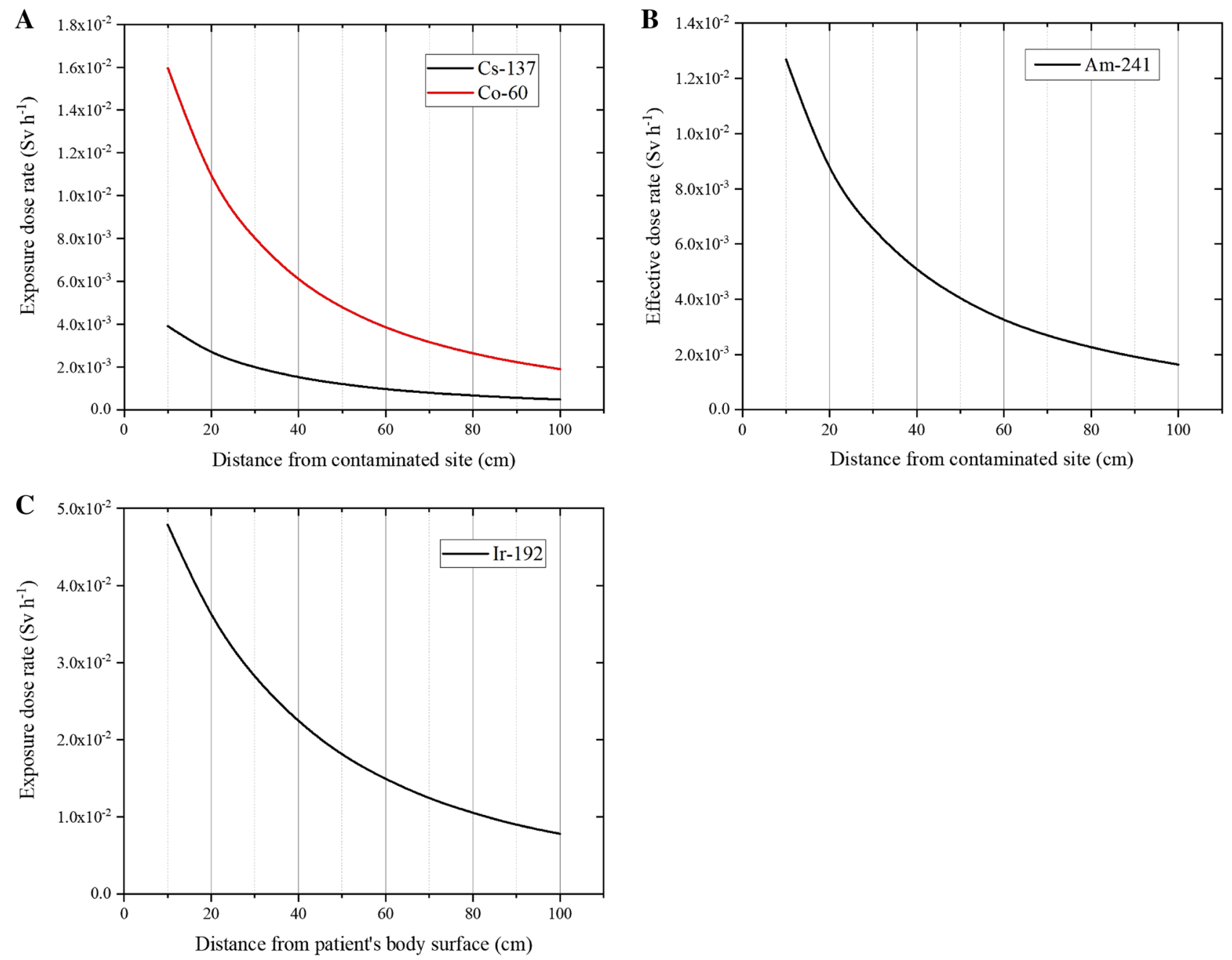

Figure 4. Exposure doses of an emergency medical responder who cares for a patient with highly radioactive contamination during a radiological accident. Table 1 shows the detailed assumptions for these scenarios (Scenario 2). (A) Radiological accidents associated with the theft of medical/industrial radiation sources, assuming a 10-GBq source. (B) Radiological accidents caused by mishandling of industrial radiation source, assuming a 185-GBq source. (C) Radiological accidents related to mishandling of a medical radiation source (e.g., for brachytherapy), assuming a 137-GBq source.

\begin{tabular}{|c|c|c|c|c|c|}
\hline & \multirow[b]{2}{*}{ Radionuclides } & \multicolumn{4}{|c|}{ Expected time to reach dose limits } \\
\hline & & $1 \mathrm{mSv}(\mathrm{min})$ & $20 \mathrm{mSv}$ & $50 \mathrm{mSv}(\mathrm{h})$ & $100 \mathrm{mSv}(\mathrm{h})$ \\
\hline \multirow{4}{*}{ Scenario 2 (from Table 1) } & ${ }^{60} \mathrm{Co}$ & 3.76 & $1.24 \mathrm{~h}$ & 3.13 & 6.27 \\
\hline & ${ }^{137} \mathrm{Cs}$ & 15.25 & $5.11 \mathrm{~h}$ & 12.79 & 25.58 \\
\hline & ${ }^{241} \mathrm{Am}$ & 4.73 & $1.57 \mathrm{~h}$ & 3.94 & 7.88 \\
\hline & ${ }^{192} \mathrm{Ir}$ & 1.25 & $25.06 \mathrm{~min}$ & 1.04 & 2.09 \\
\hline
\end{tabular}

Table 2. Expected time to reach various dose limits. The expected times were derived from the dose rates at a distance of $10 \mathrm{~cm}$ from the patient. 


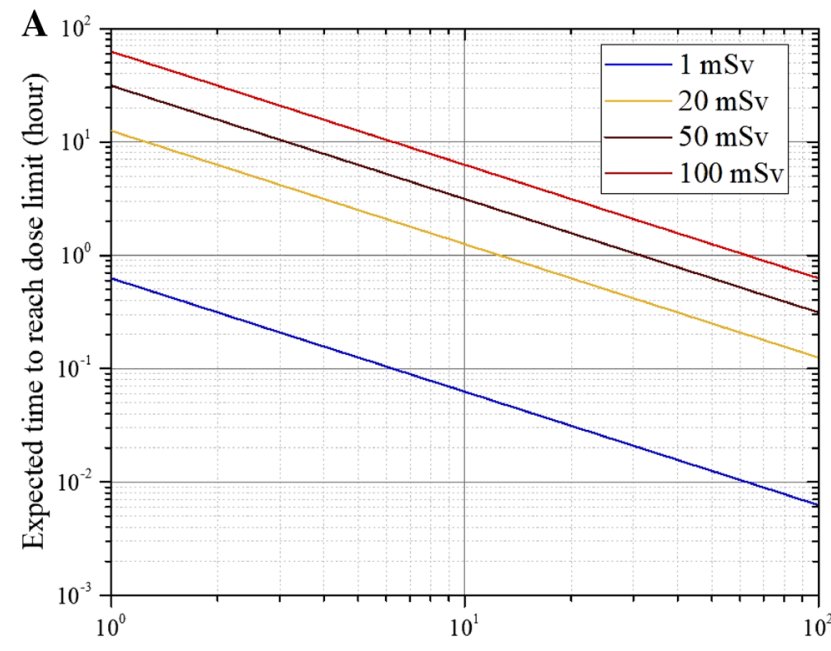

Contamination level of $\mathrm{Co}-60(\mathrm{GBq})$

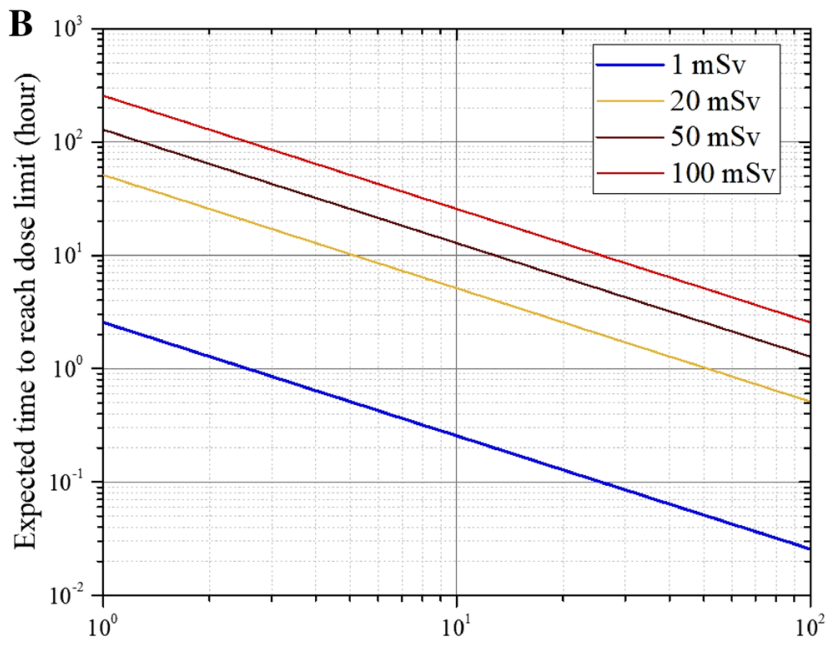

Contamination level of Cs-137 (GBq)

Figure 5. Exposure doses of an emergency medical responder caring for a patient contaminated by a highly radioactive radiation source at a distance of $10 \mathrm{~cm}$ for each contamination amount. When the radionuclide is (A) ${ }^{60} \mathrm{Co}$ or $(\mathbf{B}){ }^{137} \mathrm{Cs}$, a point-source-like contamination (radius $1.25 \mathrm{~cm}$ ) is assumed on the back of the hand (see Scenario 2 in Table 1).

Received: 3 December 2020; Accepted: 19 February 2021

Published online: 17 March 2021

\section{References}

1. International Atomic Energy Agency (IAEA). The Fukushima Daiichi Accident; Reported by the Director General 1-220 (IAEA, 2015).

2. Hasegawa, A. et al. Health effects of radiation and other health problems in the aftermath of nuclear accidents, with an emphasis on Fukushima. Lancet 386(9992), 479-488 (2015).

3. Ohtsuru, A. et al. Nuclear disasters and health: Lessons learned, challenges, and proposals. Lancet 386(9992), 489-497 (2015).

4. International Atomic Energy Agency (IAEA). The Radiological Accident in Goiania 1-157 (IAEA, Vienna, 1998).

5. Marshall, E. Juarez: An unprecedented radiation accident. Science 223(4641), 1152-1154 (1984).

6. Leonard, R. B. \& Ricks, R. C. Emergency department radiation accident protocol. Ann. Emerg. Med. 9(9), 462-470 (1980).

7. Hachiya, M. \& Akashi, M. Lessons learned from the accident at the Fukushima Dai-ichi Nuclear Power Plant-more than basic knowledge: Education and its effects improve the preparedness and response to radiation emergency. Radiat. Prot. Dosimetry 171(1), 27-31 (2016).

8. International Atomic Energy Agency (IAEA). IAEA-TECDOC-1162; Generic Procedures for Assessment and Response During a Radiological Emergency 1-193 (IAEA, 2000).

9. International Atomic Energy Agency (IAEA). Cytogenetic Analysis for Radiation Dose Assessment 1-138 (IAEA, Vienna, 2001).

10. International Atomic Energy Agency (IAEA). Operational Intervention Levels for Reactor Emergency and Methodology for Their Derivation 1-163 (IAEA, 2017).

11. Fukushima, Y., Yoshida, K., Orita, M., Takamura, N. \& Yamashita, S. Factors relating to anxiety among medical teams dispatched to the Fukushima Nuclear Power Plant disaster. Int. J. Disaster Risk Reduct. 42, 101330. https://doi.org/10.1016/j.ijdrr.2019.10133 $0(2020)$.

12. Sato, T. et al. Features of particle and heavy ion transport code system PHITS version 3.02. J. Nucl. Sci. Technol. 55, 684-690 (2018).

13. Sato, T. et al. Overview of particle and heavy ion transport code system PHITS. Ann. Nucl. Energy 82, 110-115 (2014).

14. Iwamoto, Y. et al. Benchmark study of the recent version of the PHITS code. J. Nucl. Sci. Technol. 54(5), 617-635 (2017).

15. Shinohara, A. et al. Rational evaluation of the therapeutic effect and dosimetry of auger electrons for radionuclide therapy in a cell culture model. Ann. Nucl. Med. 32(2), 114-122 (2018).

16. Kumada, H., Nakamura, T., Komeda, M. \& Matsumura, A. Development of a new multi-modal Monte-Carlo radiotherapy planning system. Appl. Radiat. Isot. 67(7-8), S118-S121 (2009).

17. Sato, T. Evaluation of world population-weighted effective dose due to cosmic ray exposure. Sci. Rep. 6, 33932 (2016)

18. International Commission on Radiological Protection (ICRP), International Commission on Radiation Units and Measurements (ICRU). ICRP publication 110; adult reference computational phantoms joint ICRP/ICRU report. Ann. ICRP 39(2), 1-170 (2009).

19. Briesmeister JF. MCNP ${ }^{\mathrm{TM}}$ - - a general Monte Carlo N-particle transport code. Los Alamos, NM. Los Alamos National Laboratory: Technical report LA-13709-M (2000).

20. Smith, J. M., Ansari, A. \& Harper, F. T. Hospital management of mass radiological casualties: Reassessing exposures from contaminated victims of an exploded radiological dispersal device. Health Phys. 89(5), 513-520 (2005).

21. Van Tuyle, G. J. \& Mullen, E. Life-cycle of large radiological sources-assessing RDD concerns and options. Los Alamos, NM. Los Alamos National Laboratory: Report LA-UR-03-6281 (2009).

22. International Commission on Radiological Protection (ICRP). ICRP publication 103; the 2007 Recommendations of the International Commission on Radiological Protection. Ann. ICRP 37(2-4), 1-339 (2007).

23. National Council on Radiation Protection and Measurements (NCRP). Report Number 165; Responding to a Radiological or Nuclear Terrorism Incident: A Guide for Decision Makers 1-211 (NCRP, 2010).

24. Kazzi, Z., Buzzell, J., Bertelli, L. \& Christensen, D. Emergency department management of patients internally contaminated with radioactive material. Emerg. Med. Clin. N. Am. 33(1), 179-196 (2015).

25. International Atomic Energy Agency (IAEA). Medical Management of Persons Internally Contaminated with Radionuclides in a Nuclear or Radiological Emergency 1-119 (IAEA, 2018). 
26. National Council on Radiation Protection and Measurements (NCRP). NCRP Report 161, Management of persons contaminated with radionuclides. Bethesda, MD: NCRP. (2008). https://ncrponline.org/shop/reports/report-no-161-i-management-of-perso ns-contaminated-with-radionuclides-handbook/. Accessed Sept 12, 2020.

27. Sato, Y. et al. Factors associated with nurses' intention to leave their jobs after the Fukushima Daiichi Nuclear Power plant accident. PLoS One 10(3), e0122389 (2015).

28. Akashi, M., Kumagaya, K., Kondo, H. \& Hirose, Y. Concerns of Disaster Medical Assistance Team (DMAT) members about troubles at the nuclear power plant: Experience from the Niigata Chuetsu-Oki earthquake, 16 July 2007, Japan. Health Phys. 98(6), 804-809 (2010).

29. International Atomic Energy Agency (IAEA). Guidance for Medical Physicists Responding to a Nuclear or Radiological Emergency 1-86 (IAEA, Vienna, 2020).

30. Coeytaux, K. et al. Reported radiation overexposure accidents worldwide, 1980-2013: A systematic review. PLoS One 10(3), e0118709 (2015).

\section{Author contributions}

T.T. contributed to the construction of the simulation models, verified the accuracy of all experiments, searched for the references, and wrote the manuscript. Y.S., M.S., and K.N. contributed to the construction of the simulation model. K.I., H.Y., S.T., and I.K. provided advice regarding the simulation conditions, organizing the data, and verifying the accuracy of all experiments.

\section{Funding}

Funding was provided by Interdisciplinary Collaborative Research Grant for Young Scientists, Hirosaki University and The Program of the Network-type Joint Usage/Research Center for Radiation Disaster Medical Science.

\section{Competing interests}

The authors declare no competing interests.

\section{Additional information}

Correspondence and requests for materials should be addressed to I.K.

Reprints and permissions information is available at www.nature.com/reprints.

Publisher's note Springer Nature remains neutral with regard to jurisdictional claims in published maps and institutional affiliations.

(c) (i) Open Access This article is licensed under a Creative Commons Attribution 4.0 International

License, which permits use, sharing, adaptation, distribution and reproduction in any medium or format, as long as you give appropriate credit to the original author(s) and the source, provide a link to the Creative Commons licence, and indicate if changes were made. The images or other third party material in this article are included in the article's Creative Commons licence, unless indicated otherwise in a credit line to the material. If material is not included in the article's Creative Commons licence and your intended use is not permitted by statutory regulation or exceeds the permitted use, you will need to obtain permission directly from the copyright holder. To view a copy of this licence, visit http://creativecommons.org/licenses/by/4.0/.

(C) The Author(s) 2021 